\title{
Blacks in science: a US national scandal?
}

ONE of the more striking things noticed by a foreign visitor to a US research laboratory is the extremely low number of black scientists that one meets. Despite more than a decade's concerted efforts to redress racial discrimination and provide educational opportunities for minority groups, the scientific community remains dominated by its white, primarily male, members. And the recent decision of the Supreme Court in the Bakke case. namely that discriminating in favour of minority groups in university enrolment programmes is constitutional but that too rigid an approach is not, has done little to help the situation.

If the position of minority groups in medical schoolsthe subject of the Bakke decision-is bad, that in science is even bleaker. In a country where blacks make up 15 per cent of the 15 to 21 age group, and 10.7 per cent of the university population. only 4.7 per cent of physical science undergraduates, for example, are black. Even more telling are the figures for PhDs. In a study of 'women and minority PhDs in the 1970s' published recently by the National Research Council, there were only 20 blacks among the 3,166 males receiving doctorates in the physical sciences between 1973 and 1976 (for females the proportion was slightly higher-3 out of 113 -but the different totals illustrate another aspect of the problem).

There are no easy solutions. No one seriously believes that the situation can be improved merely by imposing quota restrictions on entrance to university science faculties; nor, for example, by practising reverse discrimination in the award of postgraduate studentships or research grants. For the problem is closely related to broader factors which encourage or rule out access to and interest in scientific knowledge at a much earlier point in the educational spectrum.

The potential young black scientist, for example, finds the dice loaded against him or her in ways that range from the advice against scientific careers given by teachers and counsellors to the poor quality of mathematics teaching in many of the predominantly black elementary and secondary schools.

From this point of view, a recent decision of the National Science Foundation to award a grant of $\$ 2.8 \mathrm{~m}$ to the University of Atlanta to set up a Resource Center for Science and Engineering can only be welcomed. The centre will not only make its scientific resources available to a network of mainly black universities and colleges in the south eastern states, but will also involve primary school children from low income neighbourhoods surrounding the university in a 'Saturday science academy'.

The university feels strongly that the NSF should be given sufficient money to establish similar centres throughout the country. Certainly some such major commitment is required if the low level of blacks-indeed of all minority groups - in science is not to remain a national scandal. But the political climate of the US is moving away from the more liberal outlook of the early 1970s. One need only remark the difficulties being experienced by supporters of the equal rights amendment in obtaining ratification from the necessary number of states, or the likely effects of California's proposition 13 on reducing spending on educational programmes for minority groups in general. The present may look bleak. But the future does not look that much brighter.

\section{Reproductive technology: whose baby?}

THE successful birth last week, in the north country town of Oldham. of a healthy baby conceived by in vitro fertilisation has been almost universally welcomed and hailed as an important advance in the treatment of certain types of infertility. The baby girl was born to a woman unable to conceive as a result of blocked Fallopian tubes. An ovum was removed surgically and fertilised in vitro by her husband's sperm. The fertilised egg was then reimplanted into the mother's uterus where it developed as in a normal pregnancy. The crucial advance in this case was the successful implantation: the first successful in vitro fertilisation of a human egg was reported in 1969. Dr Robert Edwards of Cambridge and the Oldham gynaecologist Mr Patrick Steptoe are reported to have made a large number of attempts to implant a fertilised egg back into the mother, but without success, although similar procedures in animals have become almost routine. Providing the correct hormonal treatment to make the uterus receptive is far more difficult in humans than in animals because of the unpredictability of the human menstrual cycle. This problem has now apparently been overcome and endocrinologists are no doubt looking forward to the promised paper in which the details will be specified.

There can be few, if any, ethical objections to the recent success. The child is both the genetic and legal offspring of her parents, and used in this way the technique is simply another. particularly sophisticated, means of relieving infertility and its attendant unhappiness. However, some of the implications of the foreseeable extensions of this work might be less simply be resolved. One proposal is that the fertilised egg might be implanted into a foster mother, in cases where the genetic mother was unable to bear the baby. Whose child would it be? If the practice followed in cases of artificial insemination by a donor other than the husband were followed, the legal parents would be the woman who bore the child, and her husband, if any. To 